\title{
Políticas públicas, meio ambiente e desenvolvimento local: uma análise a partir do Plano de Manejo na Vila Algodoal (PA)
}

\section{Public policies, environment and local development: an analysis from the management plan in Vila Algodoal (PA, Brazil)}

Julio de Pádua Lopes Menezes, Marco Valério de Albuquerque Vinagre, Mayra Hermínia Simões Hamad Farias do Couto, Igor Charles Castor Alves, Kamila Batista da Silva Barbosa

RESUMO: O presente artigo apresenta um debate sobre políticas públicas associadas ao meio ambiente. Apresenta como objetivos centrais um levantamento do conceito do que são as políticas públicas do ponto de vista da consolidação da mesma como ciência, a revisão do contexto histórico do movimento ambientalista e exemplos de políticas públicas a partir do plano de manejo da APA Algodoal-Maiandeua, no município de Maracanã no Pará. Identifica-se que, apesar da boa iniciativa da proteção socioambiental pela legislação estabelecida pelo plano de manejo observado na APA AlgodoalMaiandeua, tais políticas não vem sendo, de fato, condizentes com o desenvolvimento local, pois ao analisar os indicadores como o da ocupação, do abastecimento de água e do saneamento, os mesmos demonstram que necessitam ser melhorados, haja vista que uma APA deve integrar o desenvolvimento local sustentável.

PALAVRAS-CHAVE: Políticas Públicas; Meio Ambiente; Desenvolvimento Local.

ABSTRACT: This article presents a debate about public policies associated with the environment. It presents as central objectives, a survey of the concept of public policies from the point of view of the consolidation of the same as science, a revision of the historical context of the environmental movement and examples of public policies from the APA Algodoal-Maiandeua management plan, in the municipality of Maracanã do Pará. It is identified that, despite the good initiative of socio-environmental protection by the legislation established by the management plan observed at the APA Algodoal-Maiandeua, these policies are not in fact consistent with local development, since analyzing indicators such as occupation, water supply and sanitation, they demonstrate that they need to be improved, since an APA should integrate sustainable local development.

KEYWORDS: Public Policy; Environment; Local Development. 


\title{
Introdução
}

O conceito de políticas públicas pode ser entendido, de maneira simples e direta, como: "a totalidade de ações, metas e planos que os governos (nacionais, estaduais ou municipais) traçam para alcançar o bemestar da sociedade e o interesse público" (SEBRAE, 2008, p.1). Portanto, pode ser compreendida como toda ação ou programa promovido pelo Estado a fim de garantir na prática direitos previstos na legislação que assegurem o bem estar social.

De acordo com Souza (2006), as políticas públicas são descritas como disciplina acadêmica surgida nos Estados Unidos, que tem como precursores H. Laswell, H. Simon, C. Lindblom e D. Easton, que incitaram ideias sobre o assunto logo após o período da grande crise de 1929, usaram de variadas e inovadoras contribuições ocorridas para a efetivação desse conhecimento como ciência.

$\mathrm{Na}$ atualidade, podemos compreender melhor as definições do estudo de políticas públicas descrita por Souza $(2006$, p.23) da seguinte forma:

\begin{abstract}
Não existe uma única, nem melhor, definição sobre o que seja política pública. Mead (1995) a define como um campo dentro do estudo da política que analisa o governo à luz de grandes questões públicas e Lynn (1980), como um conjunto de ações do governo que irão produzir efeitos específicos. Peters (1986) segue o mesmo veio: política pública é a soma das atividades dos governos, que agem diretamente ou através de delegação, e que influenciam a vida dos cidadãos. Dye (1984) sintetiza a definição de política pública como "o que o governo escolhe fazer ou não fazer" A definição mais conhecida continua sendo a de Laswell, ou seja, decisões e análises sobre política pública implicam responder às seguintes questões: quem ganha 0 quê, por quê e que diferença faz.
\end{abstract}

Portanto, fica evidente que o conceito de políticas públicas ganha espaço à medida que aumentam as demandas das sociedades em nome de um maior apelo por regimes de governos democráticos, representando avanços na melhoria das condições de vida da população.

Com isso, o conceito de políticas públicas fica associado ao conceito de gestão pública (Estado) em função das demandas da sociedade como abordado por Benedito e Menezes (2013 p.58):

[...]o Estado é reconhecido como o local de reconhecimento, debate e resolução dos problemas existentes em uma determinada sociedade e, a política pública é responsável pela identificação, planejamento e solução destes problemas através de uma ação estratégica que envolva sociedade e Estado. 
De maneira geral as políticas públicas marcam campos multidisciplinares teórico-conceituais com foco nas explicações sobre a natureza de seus processos, convergindo assim com o interesse comum de diversas áreas do conhecimento, tais como a economia, a ciência política, a sociologia, a antropologia, a geografia, o planejamento, a gestão e as ciências sociais aplicadas, tendo contribuído para avanços teóricos e empíricos do conhecimento (SOUZA, 2006).

Desta forma, após a primeira Guerra Mundial ocorreu a necessidade dos Estados buscarem a garantia dos interesses sociais de sua população. Visto que as medidas de maior intervenção do Estado, em um contexto liberal, caminhavam para uma preocupação "cidadã", culminando no Estado de bem-estar social (OLIVEIRA; QUINTANA, 2017).

Assim, ficam asseguradas as demandas constituídas na lei que podem vir a ser garantidas por meio de uma política pública e de novas reivindicações de acordo com a necessidade da sociedade. Para tanto, o modelo brasileiro, segundo Locks (2012, p.47), ocorreu de forma gradual em que descreve "a abertura política da agenda pública ocorreu com o lento processo de redemocratização que se iniciou a partir da década de 1980 e culminou com a Constituição de 1988". Nesse sentido, não é possível atender todas as demandas da sociedade representada por grupos diversos, sendo necessário criar estratégias para priorizar 0 atendimento das demandas (planejamento, execução e avaliação) por meio de processos, como descrito por Benedito e Menezes (2013 p.58).

\begin{abstract}
As Políticas Públicas possuem um processo de formação de longo e médio prazo, consistentes nas fases de reconhecimento do problema público; formação de uma agenda pública; formulação da Política Pública em si; processo político de tomada de decisão de implementação da Política Pública; execução da Política Pública; acompanhamento, monitoramento e avaliação da Política Pública e; por fim, a decisão sobre a continuidade, reestruturação ou extinção da Política Pública.
\end{abstract}

Para tanto, ao aprofundar o conceito de políticas públicas existe uma série de etapas e processos a serem executados em diversas esferas de governo, passando pelo processo de formação de agenda, formulação de políticas, execução, acompanhamento e avaliação, sendo ações de atribuições em nível federal, estadual e municipal como orientam Farah (2016), Noronha (2006), Souza (2006), Almeida e De Paula (2014).

Souza (2006, p.28) contribui ao descrever alguns modelos explicativos que foram desenvolvidos para "entender melhor como e por que o governo faz ou deixa de fazer alguma ação que repercutirá na vida dos cidadãos". Em relação à classificação é considerado um conjunto de etapas pelas quais uma política pública passa até que seja colocada em prática, e usualmente é conhecido como ciclo de políticas públicas, que podem ser divididas em modelos de formulação e análise. 
De acordo com Souza (2006, p.24), a política distributiva que utiliza "decisões tomadas pelo governo, que desconsideram a questão dos recursos limitados, gerando impactos mais individuais do que universais, ao privilegiar certos grupos sociais ou regiões, em detrimento do todo". Enquanto as políticas regulatórias têm maior visibilidade popular, pois envolvem interesses de grupos e burocracia. Já as políticas redistributivas, também conhecidas como políticas sociais universais abrangem um número maior de pessoas, promovendo perdas e prazos limitados para grupos de pessoas. Há ainda, as políticas constitutivas, que se caracterizam por estabelecerem procedimentos e ações presentes nas legislações. Assim, "cada uma dessas políticas públicas vai gerar pontos ou grupos de vetos e de apoios diferentes, processando-se, portanto, dentro do sistema político de forma também diferente" (SOUZA, 2006, p.28).

Portanto, pode ser observado que a existência de ciclos é importante na implantação das políticas públicas, sendo fundamental para que a análise dessas políticas seja de fato efetivada e o processo pode ser considerado um modelo de aprendizado, já visto, que na prática dos governos tal ciclo pode apresentar diferenciações. Mesmo assim é fundamental que cada cidadão tenha consciência e exija o comprimento dos seus direitos.

Cabe ressaltar, de acordo com Jacobi (2003), que a Constituição brasileira de 1988, passou a reconhecer direitos universais, com um olhar às questões ambientais. Assim, o meio ambiente é também reconhecido como um direito de todos, com uma legislação específica, a exemplo: a Política Nacional do Meio Ambiente, além da Carta da República (BRASIL, 1988).

Outro avanço da política ambiental brasileira é a Lei 9.985/2000, que, entre outras ações, estabelece o conceito de Área de Proteção Ambiental (APA), modalidade de uso de recursos naturais dentro do grupo das Unidades de Conservação (UC) de uso sustentável. Tais unidades são integrantes do Sistema Nacional de Unidades de Conservação da Natureza (SNUC). Estas áreas são de alta importância biológica e de prioridade de ações para conservação, uso sustentável e repartição dos benefícios da biodiversidade brasileira (BRASIL, 2000).

Deste modo, a gestão dos recursos naturais em APA deve ser organizada localmente, a partir de órgãos públicos ambientais, associadas com as comunidades locais, por meio de instrumentos técnicos. Entre eles, é atualmente utilizado o Plano de Manejo entendido aqui como um "documento técnico [...] como fundamento nos objetivos gerais de uma unidade de conservação, se estabelece o seu zoneamento e as normas que devem presidir o uso da área e o manejo dos recursos naturais [...]." (BRASIL, 2000, Art. 20 XVII).

Entre as políticas públicas que demandam grande atenção nessas áreas destacam-se aquelas que tratam da questão da água. Dada a importância que a mesma tem para os seres vivos, no tocante aos seus valores sociais, econômicos e ecológicos sendo concebida como um bem de uso comum, devendo ser direito de toda população. 
A água como recurso em áreas de APA, especialmente no que se refere o consumo humano, é extraída de reservas subterrâneas, as quais vêm sendo submetidas a um grande impacto ambiental devido à excessiva exploração dos aquíferos costeiros, em decorrência do aumento populacional, o que proporciona um aumento da demanda desordenada de tal recurso. Outros problemas encontrados, diz respeito ao uso coleta de esgoto que está acarretando o aumento da incidência de doenças associado a grande quantidade de resíduos produzidos pelo aumento populacional da APA, promovido pelo turismo em longos feriados.

O objetivo geral do artigo é contribuir para as discussões sobre as públicas associadas ao desenvolvimento socioambiental em Áreas de Proteção Ambiental (APA), a partir da identificação de indicadores como: água, saneamento básico e o descarte de resíduos sólidos, analisados a partir do plano de manejo local. $O$ artigo tem como campo de estudo a vila de Algodoal, localizada na APA Algodoal-Maiandeua. Para um melhor entendimento, o estudo foi dividido em (dois) tópicos, que serão descritos a seguir:

No tópico denominado "O contexto ambiental e as políticas públicas", será mostrada uma contextualização do processo histórico de degradação do meio ambiente e a necessidade de se propor medidas de desenvolvimento no contexto (econômico, político, social e ambiental), com vistas a possibilitar um modelo de desenvolvimento sustentável. No Brasil, a constituição de 1988 favorece a consolidação de uma legislação ambiental, com a preocupação em estabelecer preocupações ambientais a partir de políticas públicas.

O tópico seguinte descreverá políticas públicas no contexto socioambiental como já intitulado de "Indicadores socioambientais no contexto do plano de manejo na vila de Algodoal". Como exemplo disso, será citado o caso da gestão ambiental a partir da adoção do manejo na APA Algodoal-Maiandeua situada no município de Maracanã, estado do Pará, como observado na (Figura 1).

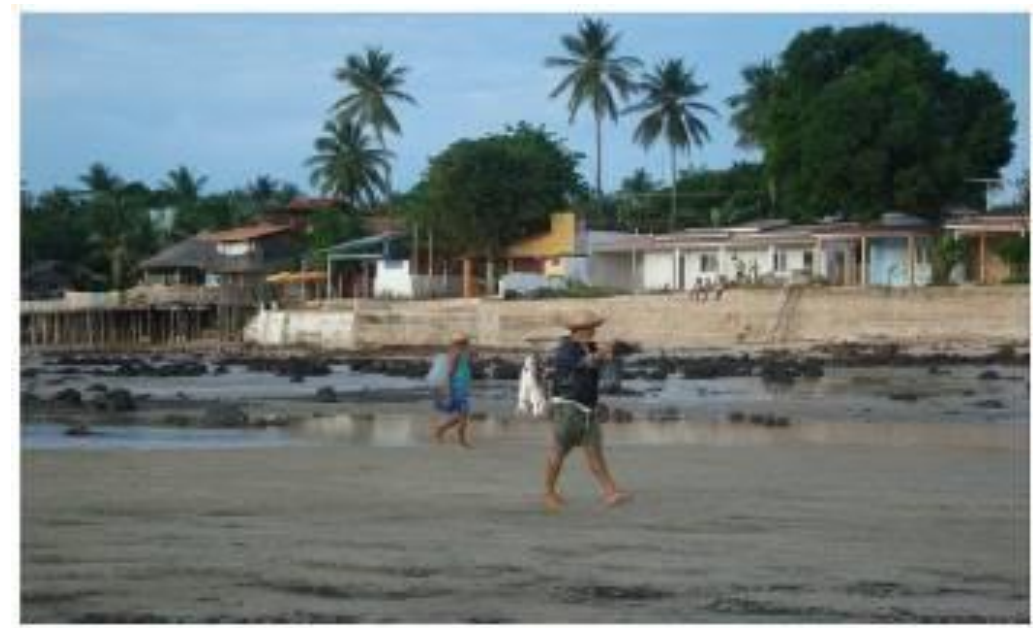

Figura 1: Orla da vila de Algodoal. Fonte: Pará (2010).

Figure 1: Algodoal village waterfront. Source: Pará (2010). 
O objeto da pesquisa é a APA localizada na vila de Algodoal situada no município de Maracanã, estado do Pará sob as coordenadas geográficas 47³2'25,590"W e 0³8'14,998'S, como pode ser observada na (Figura 2).

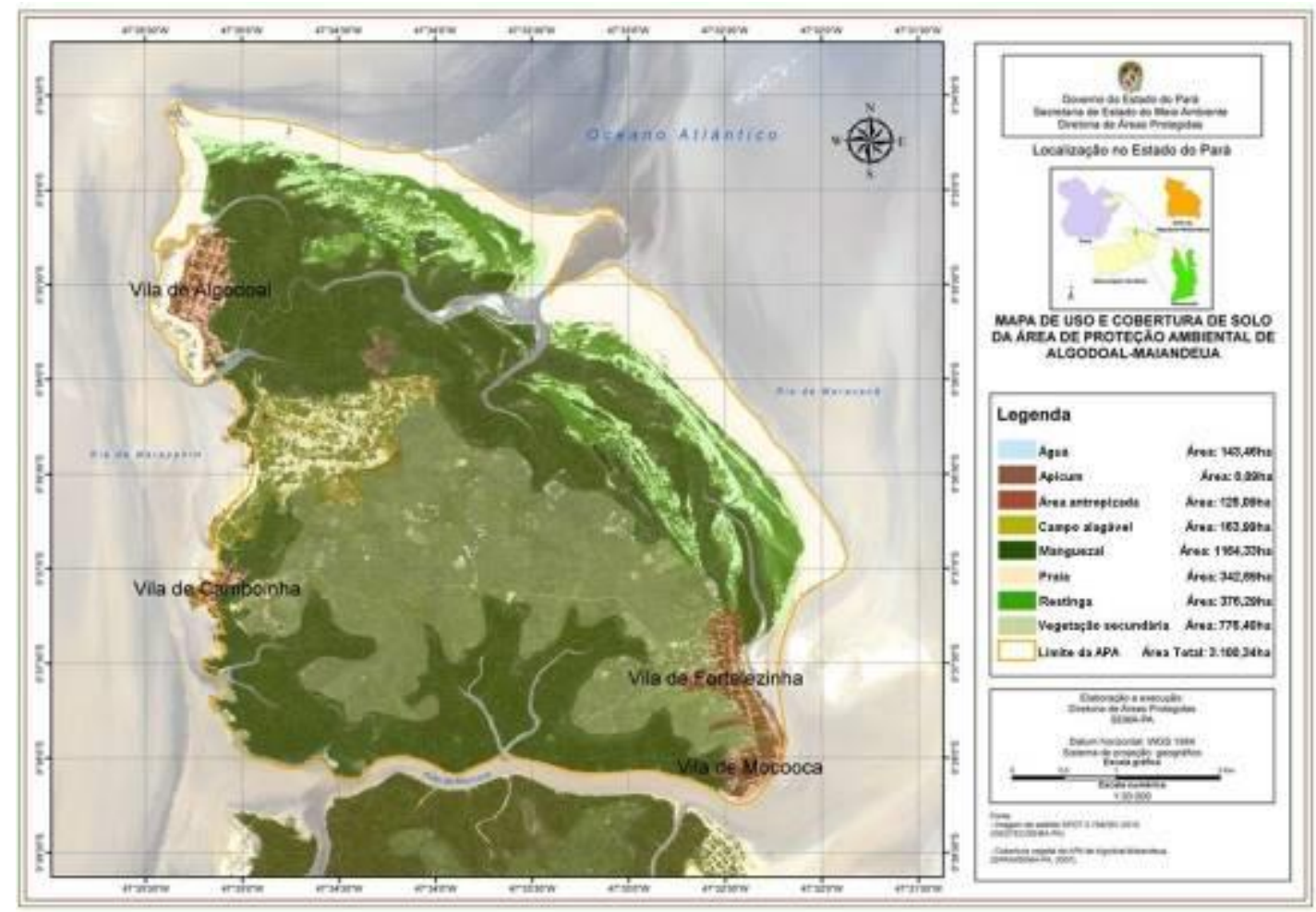

Figura 2. Localização da vila de Algodoal. Fonte: Adaptado PARÁ (2012).

Figure 2. Location of the village of Algodoal. Source: Adapted PARÁ (2012).

Assim, os próximos tópicos apresentarão alguns elementos das políticas públicas associadas ao desenvolvimento local sob o ponto de vista do plano de manejo da APA de Algodoal.

\section{O contexto ambiental e as políticas públicas}

O modelo político econômico que propõe um regime de acumulação e flexibilização de contratos de trabalho, resulta na desigualdade social e consequentemente na pobreza, sobretudo em países considerados em desenvolvimento (NORONHA, 2006). Para tanto, em nações capitalistas periféricas, especialmente o Brasil, as políticas praticadas, são marcadas pelo rápido crescimento econômico, baseada na industrialização e resultando em uma veloz urbanização de suas cidades. Como resultado, tais medidas provocaram a degradação ambiental desenfreada gerando prejuízos para a natureza e consequentemente ao homem.

Deste modo, pode se perceber que tal degradação foi acentuada ao longo das últimas décadas com consequências alarmantes no contexto mundial e sobre aspecto econômico, políticos, sociais e ambientais. Assim, nasce a preocupação em estabelecer um elo entre a preocupação ambiental e as políticas públicas nas escalas global, nacional e local. 
De acordo com Casagrande Jr. (2004) na década de 1960 e 1970, a criação do Clube de Roma (1968) e a realização da I Conferência da Organização das Nações Unidas sobre Meio Ambiente Humano, assim como, as Conferências de Estocolmo (1972), Nairóbi (1982), Rio (1992) e seus desdobramentos, alteraram o discurso ambiental, e a forma de se pensar e adotar políticas que envolvam aspectos econômicos, sociais e o meio ambiente. As transformações políticas, econômicas e ambientais vêm interferindo nas relações da sociedade com o meio ambiente, como apontado por Gouveia (2012, p.1).

O desenvolvimento econômico, o crescimento populacional, a urbanização e a revolução tecnológica vêm sendo acompanhados por alterações no estilo de vida e nos modos de produção e consumo da população. Como decorrência direta desses processos, vem ocorrendo um aumento na produção de resíduos sólidos, tanto em quantidade como em diversidade, principalmente nos grandes centros urbanos. Além do acréscimo na quantidade, os resíduos produzidos atualmente passaram a abrigar em sua composição elementos sintéticos e perigosos aos ecossistemas e à saúde humana, em virtude das novas tecnologias incorporadas ao cotidiano.

Nesse contexto, ganham maior visibilidade os debates que relacionam as questões ambientais ao desenvolvimento produtivo. A partir dos anos 1980 o termo eco-desenvolvimento passa a ser denominado de "desenvolvimento sustentável" com ênfase em propostas para o equilíbrio ambiental, social e econômico. E os países economicamente desenvolvidos passam a dar mais destaque à questão da sustentabilidade no campo ambiental, originando o uso do termo socioambiental. (CASAGRANDE JR, 2004).

Diante do exposto, há uma convergência para um movimento mundial de conscientização de problemas ambientais que passam a serem incorporadas a uma agenda verde, tentativa de incluir questões ambientais nas discussões das políticas públicas de uma sociedade, ganhando espaço com a realização da Eco- $92^{1}$ em que é considerado a proteção dos recursos naturais e dos ecossistemas; ganham visibilidade questões referentes a problemas relacionados ao meio ambiente e a pobreza da população. Logo, ocorre uma tentativa de aliar duas agendas até então separadas: a ambiental e a da pobreza, como demonstra Jacobi (2003, p.194)

o desenvolvimento sustentável não se refere especificamente a um problema limitado de adequações ecológicas de um processo social, mas a uma estratégia ou um modelo múltiplo para a sociedade, que deve levar em conta tanto a viabilidade econômica como a ecológica. 
No contexto brasileiro, as políticas públicas vinculadas a questões ambientais foram favorecidas em grande parte pela aprovação da constituição de 1988:

[...] Dentre os princípios norteadores da ordem econômica, a Constituição de 1988 trouxe os seguintes: a soberania nacional, a propriedade privada, a função social da propriedade, a livre concorrência, a defesa do consumidor, a defesa do meio ambiente, a redução das desigualdades, a busca pelo pleno emprego e o tratamento favorecido para empresas de pequeno porte.(OLIVEIRA; QUINTANA, 2017 p.5)

A Política Nacional de Meio Ambiente prevê a conservação da natureza, a manutenção da biodiversidade, a promoção da qualidade de vida das populações humanas, e o desenvolvimento sustentável (BRASIL, 2000). Como proposta de integrar as questões ambientais as demandas políticas.

Portanto, fica evidente uma maior preocupação com a questão ambiental, a partir da incorporação de tal temática na legislação brasileira, reconhecida como um direito de todos pela Política Nacional do Meio Ambiente (PNMA).

Cabe ressaltar que o modelo seguido no contexto ambiental irá influenciar na tomada de decisões nas políticas públicas brasileiras, e o conceito de sustentabilidade ganha espaço nos discursos nacionais. Como comenta Oliveira e Quintana (2017 p.15):

\begin{abstract}
Estado Socioambiental visa romper com o paradigma liberal e ir além do Estado de Bem-estar social, para adotar um modelo socioeconômico, onde economia, bem-estar social e proteção do meio ambiente convivem de maneira harmônica e o princípio da sustentabilidade surge como um princípio estruturante do Estado.
\end{abstract}

Portanto, no contexto dos discursos da necessidade de atenuar o modo de consumo que intensifica a pressão pelos recursos ambientais em detrimento de uma melhor qualidade de vida, cabe a elaboração e a formulação de políticas no contexto socioambiental, compreendendo a identificação do problema, formação da agenda, formulação de alternativas, tomada de decisão, implementação, avaliação e extinção da política, conhecendo o contexto econômico, político, social e ambiental até mesmo na geração de renda como o ecoturismo como descrito pelo Ministério do Meio Ambiente, Ecoturismo (p. 12): 
[...]um ramo do turismo que utiliza os recursos naturais e culturais de um determinado lugar e contribui para conserválos. Busca desenvolver o respeito pela natureza por meio do contato com o ambiente natural e promove o bem-estar das populações locais envolvidas.

Assim, o contexto ambiental analisado a partir das políticas públicas locais, pode gerar indicadores socioambientais que contribuía para discussões acerca de uma Gestão Ambiental mais eficaz; assim cabe agora associar se o plano de manejo de Algodoal-Maiandeual-Pará apresenta índices de qualidade socioambientais, o que será observado no próximo tópico.

\title{
Indicadores socioambientais no contexto do plano de manejo na vila de Algodoal-Maiandeua-Pará
}

As políticas públicas, quando utilizadas a serviço do cidadão podem representar uma importante ferramenta para contribuir para a redução dos possíveis impactos socioambientais presentes nos diversos ambientes humanos. Cabe aqui, demonstrar que a Gestão ambiental como política pública voltada para o meio ambiente, quando bem articulada, pode favorecer a tomada de decisões locais, melhorando as questões econômicas, sociais e ambientais de uma sociedade.

A legislação brasileira aponta instrumentos para Gestão Ambiental para o favorecimento da qualidade ambiental. O Artigo 9o da Política Nacional do Meio Ambiente (BRASIL, 1981) descreve os instrumentos a serem utilizados:

\begin{abstract}
São Instrumentos da Política Nacional do Meio Ambiente:
I - o estabelecimento de padrões de qualidade ambiental; II o zoneamento ambiental; III - a avaliação de impactos ambientais; IV - o licenciamento e a revisão de atividades efetiva ou potencialmente poluidoras; $\mathrm{V}$ - os incentivos à produção e instalação de equipamentos e a criação ou absorção de tecnologia, voltados para a melhoria da qualidade ambiental; VI - a criação de espaços territoriais especialmente protegidos pelo Poder Público federal, estadual e municipal, tais como áreas de proteção ambiental, de relevante interesse ecológico e reservas extrativistas $[\ldots]$
\end{abstract}

Possivelmente a melhor forma de conservação dos recursos naturais se dá pelo controle de uso e ocupação do solo para a manutenção de áreas silvestres, através de espaços protegidos. Assim, para Ministério do Meio Ambiente (MMA) 
as Unidades de Conservação apresentam destaque, uma vez que no âmbito da Política Nacional de Meio Ambiente, devem conservar a natureza, manter a biodiversidade, promover a qualidade de vida das populações humanas, e o desenvolvimento sustentável.

$\mathrm{Na}$ perspectiva de demonstrar na prática a efetivação da gestão ambiental, buscou-se apresentar alguns aspectos do plano de manejo da Unidade de Conservação-(UC) ${ }^{2}$.

A UC Algodoal-Maiandeua está localizada no litoral nordeste do Estado do Pará, na microrregião do Salgado município de Maracanã, foi criada pela Lei o 5.621, de 27 de novembro de 1990, apresenta ecossistemas costeiros e peculiaridades sociais e culturais (PARA, 2012). Tal UC, é da categoria Áreas de Proteção Ambiental (APA),que se caracterizar por admitir o uso sustentável dos recursos naturais e por possuir propriedades de domínio público e privado.

O planejamento da APA deve ser estabelecido a partir de um Plano de Manejo, como descrito Pará (2012 p.22):

O Plano de Manejo da APA de Algodoal-Maiandeua foi elaborado atender suas necessidades de conservação e desenvolvimento. Para o planejamento foram consideradas as orientações do Roteiro Metodológico para Elaboração de Planos de Manejo das Unidades de Conservação Estaduais do Pará.

Os objetivos do plano orientam o direcionamento de metas prioritárias para gestão da UC, com vistas no alcance das metas estabelecidas anteriormente, de acordo com situações próprias, respeitando as limitações da gestão (PARÁ, 2012).

Portanto, ao observarmos a finalidade e o objetivo do plano de manejo, é percebida uma convergência importante na implantação das políticas públicas, sobre a óptica da gestão, preservação e na sustentabilidade. Mesmo a gestão sendo praticada pelo Estado, é fundamental a participação da comunidade na tomada das decisões, para que a análise dessas políticas seja de fato efetivada.

De acordo com plano de manejo de Algodoal citado em Pará (2012, p.24 e 25):

O Decreto Federal o 4.340/2002, que regulamenta o SNUC, através de seu Artigo 17, prevê a criação de um Conselho Gestor consultivo ou deliberativo na UC, cujos membros devem ser de órgãos públicos nas esferas Federal, Estadual e Municipal, bem como representantes da Sociedade Civil, tais como: associações, comunidades cientificas e organizações não governamentais. 
Ainda de acordo com plano de manejo de Algodoal, o Conselho Gestor tem várias responsabilidades, como descrito em Pará (2012, p.25):

\begin{abstract}
Segundo esse Decreto, Art. 17, compete ao Conselho Gestor: elaborar seu regimento interno, acompanhar a elaboração, implementação e revisão do Plano de Manejo da UC; buscar a integração da Unidade de Conservação com as demais unidades e espaços territoriais especialmente protegidos e com o seu entorno, esforça-se para compatibilizar os interesses dos diversos segmentos sociais relacionados com a unidade, avaliar o orçamento da unidade e o relatório financeiro anual elaborado pelo órgão gestor, ratificar a contratação e os dispositivos do termo de parceria com Organização da Sociedade Civil de Interesse Público (OSCIP), na hipótese de gestão compartilhada da unidade; acompanhar a gestão da OSCIP e recomendar a rescisão do termo de parceria, quando constatada irregularidade; manifestar-se sobre obra ou atividade potencialmente causadora de impacto na UC, mosaico ou corredores ecológicos; propor diretrizes e ações para compatibilizar, integrar e otimizar a relação com a população do entorno.
\end{abstract}

Portanto, a composição do Conselho Gestor é formada por membros do Poder Público e da Sociedade Civil, devendo tal proporção ser paritária. Existe ainda a criação das Câmaras Técnicas - "consiste em proporcionar suporte técnico e científico, para a tomada de decisões especificas do Conselho Gestor da APA de Algodoal-Maiandeua" (PARÁ, 2012, p.24), seus membros são compostos por técnicos especializados em diversas áreas sendo os principais - meio ambiente, educação, saúde, segurança, turismo e outros.

Espada et. al (2017, p.351) comenta que:

Os conselhos gestores de Unidades de Conservação possibilitam maior participação da sociedade nas decisões governamentais sobre a forma de uso de recursos naturais coletivos. Com isso, ampliam-se as possibilidades de geração de trabalha e renda para as famílias que vivem nessas áreas a partir do uso racional de tais recursos.

Segundo Pará (2009, p.22),

os Programas de Manejo representam o mecanismo de organização e operacionalização dos objetivos definidos para o Plano de Manejo, constituindo-se, o foco de atuação do órgão gestor da Unidade. 
O planejamento tem validade de 5 anos e é executado um planejamento operacional, por meio de projetos, atividades envolvidas nos programas do Plano de Manejo. Os programas do Plano de Manejo em geral são divididos em subprogramas, que devem apresentar objetivos, metas, indicadores, ações estratégicas, potenciais parceiros. Sendo que a operação dos Programas é realizada por ações estratégicas, que são detalhadas na forma de tarefas, inseridas nos Planos Operativos Anuais (POA) da UC (PARÁ, 2012).

Logo, o Plano de Manejo Algodoal-Maiandeua é trazido aqui como exemplo de uma política que se materializa pelas decisões que devem beneficiar a comunidade em questão. No entanto, a não implantação efetiva do que foi proposto no Plano de Manejo, como pode ser evidenciada pela não prioridade em aplicá-las, acarreta problemas de caráter socioambientais, como revela Vidal e Mascarenhas (2012, p.919):

[‥] a não prioridades de políticas públicas mais especificas para a llha de Algodoal têm vulnerabilizado os grupos sociais que habitam nesse espaço, a especulação imobiliária, a falta de coleta de lixo, a falta de rede de esgoto são problemas que devem ser equacionados nos próximos anos para conter os impactos ambientais.

Porém, cabe aqui ressaltar que o objetivo desse estudo não é avaliar a política pública que trata o plano de manejo em questão, mas identificar possíveis vieses que demonstrem a necessidade de se buscar novas evidências que sejam capazes de elucidar possíveis problemas socioambientais observados a partir de indicadores no plano de manejo da vila de Algodoal na APA estudada.

Honda e Sobrinho (2018 p.316) ressaltam que

Os principais conflitos na APA de Algodoal Maiandeua são decorrentes do uso do solo: desmatamento da flora nativa, retirada areia e rochas, construções de casas em áreas irregulares, lançamento de efluentes domésticos no mar e rios, pesca predatória, depósito de lixo e da ocupação humana. Esses impactos socioambientais alteram o cenário físico da APA principalmente em relação ao uso do solo, mudança essas produzidas pelo efeito das ocupações humanas na pressão imposta pelas construções em áreas de floresta e de mangue, áreas urbanizadas de ocupação irregular em faixa de praia e terras inundáveis.

Como resultado do uso desordenado dos recursos naturais, foram analisados alguns indicadores uso do solo, uso da água e do esgoto na comunidade vila de Algodoal, que serão observados a seguir, mediante levantamento realizado no plano de manejo da referida APA. 
A distribuição da ocupação espacial da vila de Algodoal localizou e dividiu 654 lotes que podem ser observado na Tabela 1.

Tabela 1: Distribuição da ocupação espacial.

Table 1: Distribution of spatial occupation.

\begin{tabular}{ccc}
\hline \multicolumn{3}{c}{ Distribuição de lotes na vila de Algodoal } \\
\hline Uso & Quantidade & $(\%)$ \\
Residenciais & 225 & 34,4 \\
Comerciais & 58 & 8,9 \\
Hospedagem & 54 & 8,3 \\
Veraneio & 208 & 31,8 \\
Lazer & 03 & 0,5 \\
Sem uso & 58 & 8,9 \\
Outros usos & 48 & 7,3 \\
\hline
\end{tabular}

Fonte: adaptado Pará (2012).

Source: adapted Pará (2012).

A distribuição dos tipos de lotes demonstrou que a maioria $(34,4 \%)$ é residencial, totalizando 225 moradias, seguindo $(31,8 \%)$ de lotes utilizados para veraneio, com 208 unidades; após isso, os lotes comerciais e os lotes considerados sem uso correspondem a (8,9\%) ambos, perfazendo 58 lotes cada e para hospedagem (8,3\%) 54 unidades. Já os lotes que não aprestavam ocupação aparente foram considerados como de outros usos $(7,3 \%)$ total de 48 lotes; finalmente 3 unidades de lotes $(0,5 \%)$ destinam-se ao lazer.

$\mathrm{Na}$ vila de Algodoal a maioria das propriedades é abastecida com energia elétrica da Rede Celpa, e somente 2,3\% ainda usa fontes de energia tradicionais, como lamparinas a querosene ou a óleo (PARÁ, 2012).

No que diz respeito ao abastecimento de água na vila, a maioria das moradias apresenta abastecimento de água por uso de poços, como pode ser observado na Tabela 2.

Tabela 2: Abastecimento de água.

Table 2: Water supply.

\begin{tabular}{cc}
\hline \multicolumn{2}{c}{ Abastecimento de água } \\
\hline Tipo & $(\%)$ \\
Abastecimento público & 11,9 \\
Poço Amazonas & 37,3 \\
Poço Estruturado & 13,9 \\
Abast. Público e poço & Não possui \\
Outro & 18,6 \\
Sem informações & - \\
\hline
\end{tabular}

Fonte: adaptado Pará (2012).

Source: adapted Pará (2012).

O abastecimento de água se dá na vila a partir de poços Amazonas $(37,3 \%)$ em seguida outros tipos de abastecimento (18,6\%), seguindo de poços estruturados com (13,9\%) e abastecimento público com (11,9\%). 
Portanto, fica evidente que a maioria das unidades habitacionais faz o uso de poços. Os poços particulares possuem relação direta com o poder aquisitivo do usuário, pois em sua maioria são mais bem estruturados. No entanto, na Vila de Algodoal, das 581 propriedades analisadas, 41\% utilizavam alguma prática de tratamento de água (Tabela 3).

Tabela 3:Tratamento de água.

Table 3: Water treatment.

\begin{tabular}{cc}
\hline \multicolumn{2}{c}{ Tratamento de água - vila } \\
\hline Tipos & $\%$ \\
Cloro & 87,8 \\
Coada & 4,6 \\
Filtrada fervida & 6,7 \\
Sem Informação & 0,9 \\
\hline
\end{tabular}

Fonte: adaptado Pará (2012).

Source: adapted Pará (2012).

Quanto ao tratamento de água (Figura 3), os moradores que utilizam algum tipo de prática de tratamento da água, o uso do cloro teve maior incidência $(87,8 \%)$; em seguida outros tipos de tratamento de água citados foram: filtrada e fervida $(6,7 \%)$, coada $(4,6 \%)$ e uma pequena porcentagem sem informação $(0,9 \%)$.

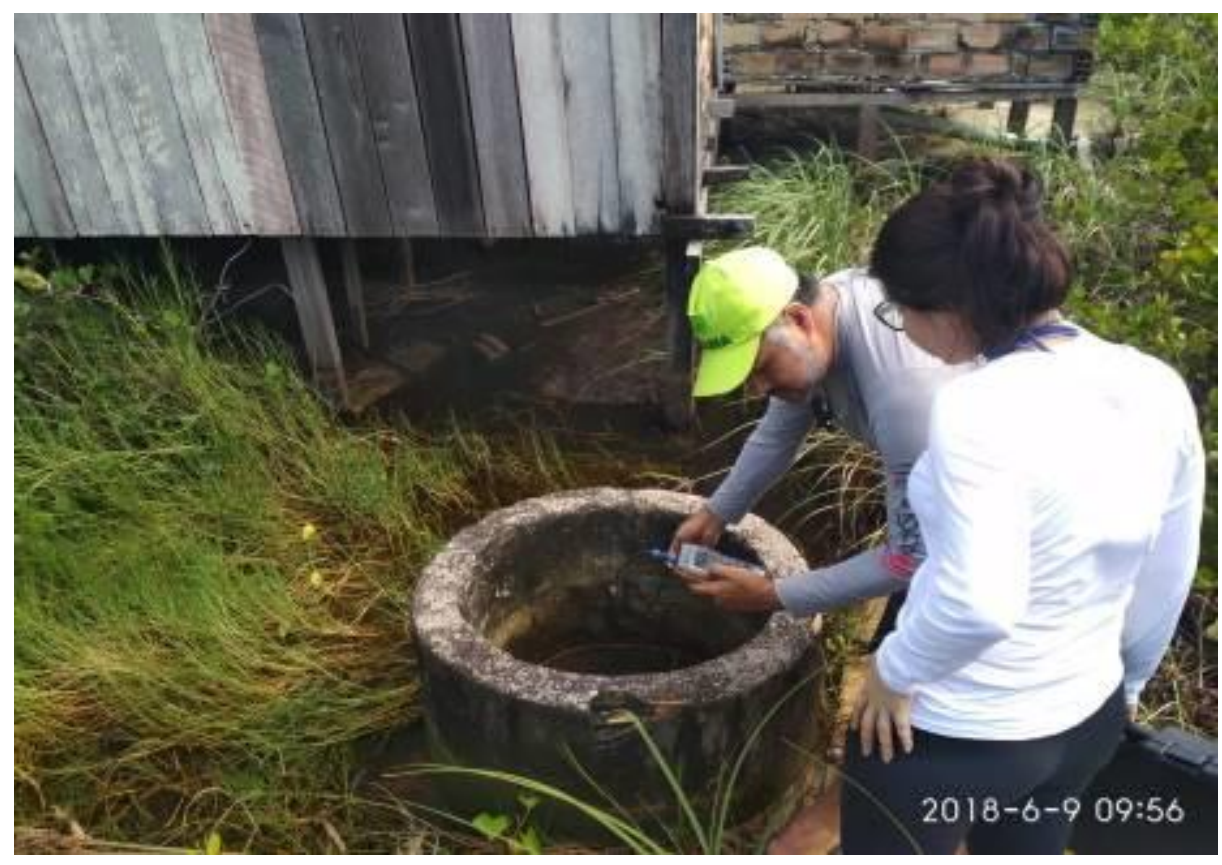

Figura 3 :Análise da água de poços na Vila de Algodoal Figure 3: Water analysis of wells in the village of Algodoal Fonte: arquivo pessoal dos próprios autores. Source: Personal archive.

Outro aspecto observado é quanto à destinação do esgoto. A prática de tratamento de esgoto utilizada pelos moradores pode ser visto na (Tabela 4). 
Tabela 4: Destinação do esgoto.

Table 4: Sewage Allocation.

\begin{tabular}{cc}
\hline \multicolumn{2}{c}{ Destinação do Esgoto - vila de Algodoal } \\
\hline Tipos & $\%$ \\
Céu aberto & 4,1 \\
Fossa negra & 2,2 \\
Fossa séptica ou sumidouro & 61,9 \\
Outros & 10,5 \\
Sem resposta & 21,3 \\
\hline
\end{tabular}

Fonte: adaptado Pará (2012).

Source: adapted Pará (2012).

No que diz respeito à destinação do esgoto, os moradores utilizam em sua grande maioria $(61,9 \%)$ fossa séptica ou sumidouro, seguido de outros tipos de destinações como céu aberto $(4,1 \%)$,fossa negra $(2,2 \%)$ e outros $(21,3)$, além de dados sem obtenção de respostas $(21,3 \%)$.

Todos esses dados demonstram que há sérios problemas com relação ao abastecimento de água, que afetam o saneamento básico, a coleta de esgoto e de resíduos sólidos, (ver figura 03), haja vista que na vila, das 581 residências (PARÁ, 2012), somente 61,8\% utilizavam fossas sépticas. Como comenta Saldanha et. al (2016) "diversos são os impactos ocasionados pelo descompasso do homem com o meio em que habita ou faz uso, o que muitas vezes, resulta na sua alteração ou degradação".

Portanto, fica evidente uma crescente preocupação com a degradação socioambiental vista em áreas de APA, como é o caso de Algodoal, com analisa Honda e Sobrinho (2018 p.316 e 317) no fragmento que segue:

\begin{abstract}
A gestão em relação ao ordenamento territorial é complexa, compartilhada e carente de uma ação conjunta e coordenada, como se verifica no estudo de campo há uma tendência de ocupação em zonas restritas para instalação e construção como em praias, dunas, mangues proximidades de lixões e de cemitérios, com esse avanço há uma ampliação horizontal para essas áreas e a malha urbana sobressai sobre as áreas rurais e espaços remanescentes de vegetação nativa, áreas de mangues também protegidos pelo Plano de Manejo.
\end{abstract}

Logo, pode ser observado alterações espaciais na ocupação da ilha, como destaca Honda e Sobrinho (2018, p.319) o "(...) aumento do turismo provocou a venda de casas da população local para veranistas e visitantes, sendo a maioria localizada próxima às praias com melhores terras e com terrenos de alto valor e dimensões grandes", tais mudanças na dinâmica de ocupação da APA vêm acarretando severas alterações no contexto, da água, saneamento, uso do solo e outros aspectos socioambientais. 
Diante de todo o exposto, apesar das políticas públicas terem papel importante para o planejamento e gestão de APAS, pode-se constatar, a partir da vila de algodoal, que os indicadores socioambientais estão longe de serem satisfatórios, especialmente por serem áreas de proteção.

Novos elementos de sustentabilidade poderiam contribuir para uma ação mitigadora no contexto do desenvolvimento sustentável local. Uma delas é o ecoturismo, que não é mencionado diretamente como política pública, mas que, se associado à gestão local, pode agregar melhorias sociais. Considerando que é uma importante atividade de geração de renda e para as comunidades locais, a mencionar Melo (2018, p.3):

\begin{abstract}
O turismo em Unidades de Conservação (UCs) cresceu substancialmente na última década e reveste-se de um caráter positivo, quando planejado e administrado em bases sustentáveis; por outro lado, os impactos podem ser potencializados na ausência de ações de monitoramento e organização da atividade.
\end{abstract}

Futuros trabalhos poderão ser importantes para o levantamento de indicadores ambientais e/ou sociais que possam inclusive fazer comparativos de indicadores e possíveis ações de consciência ambiental. E, assim, proporcionar tomadas de decisão a partir de políticas públicas locais, que influenciem de forma positiva as comunidades envolvidas.

\title{
Considerações Finais
}

Por fim, temos que as políticas globais da atualidade visam romper com uma visão liberal para ir além do Estado de Bem-estar social, a partir da adoção de um modelo socioeconômico onde economia e proteção do meio ambiente buscam conviver de maneira harmônica com princípios de sustentabilidade. Desta forma, as políticas públicas passam a ter uma centralidade na questão ambiental especialmente a partir da década de 1960 e 1970, com as discussões sobre as conferências da Organização das Nações Unidas - ONU.

No Brasil as Políticas públicas passam a ter uma centralidade na questão ambiental especialmente a partir dos anos 1980 e 1990, com a Constituição de 1988 e os desdobramentos na legislação que as integram. Assim, o que temos na atualidade é a necessidade de cada vez mais associar as questões de proteção ao meio ambiente à promoção de um desenvolvimento econômico equilibrado a exemplo da gestão ambiental, por meio de instrumentos como é o caso do plano de manejo.

A vila de Algodoal situada na APA Algodoal-Maiandeua, a rigor a vila mais povoada da APA, apresenta um número elevado de lotes destinado ao veraneio, o que demostra a presença do turismo, que pode estar impactando na ocupação desordenada na vila e afetando diretamente seus indicadores. Como verificado pelos índices de abastecimento de água e saneamento, que 
demonstram que no caso da água o uso de poços está presente na maioria das moradias e que os níveis de tratamento dessa água são realizados por cloro, mas há ainda um número de moradias sem água tratada. Aliado a isso, os índices de abastecimento de água e saneamento demonstram que no caso da água o uso de poços está presente na maioria das moradias e que os níveis de tratamento dessa água são realizados por cloro, mas há ainda um número de moradias sem água tratada. Em relação ao saneamento, no que diz respeito a coleta de esgoto, a situação é precária e requer melhorias, pois representam perigo a saúde dos habitantes.

Logo, apesar da boa iniciativa da proteção socioambiental dada pela legislação estabelecida pelo plano de manejo observado na vila APA Algodoal-Maiandeua, tais políticas não vêm sendo de fato condizentes com o desenvolvimento local equilibrado. Por isto o plano de manejo, instrumento da efetivação das políticas públicas, deve ser ajustado a realidade local levando em conta os indicadores de ocupação, abastecimento de água e saneamento entre outros, haja vista que uma APA deve integrar o desenvolvimento local sustentável.

Neste contexto, mesmo sendo necessário aprofundar o debate sobre o assunto, pode-se concluir parcialmente que as políticas públicas podem sim, quando bem associadas, contribuir para efetivação de preceitos socioambientais, na perspectiva do desenvolvimento sustentável, desde que, incluía a todos os envolvidos nos debates políticos.

\section{Referências}

ALMEIDA, B.C; PAULA, S.L. O papel da avaliação de políticas públicas no contexto dos governos locais. Planejamento e Políticas Públicas, n. 42, 2014.

BENEDITO, A.; MENEZES, D. F. N. Políticas públicas de inclusão social: o papel das empresas. Revista Ética e Filosofia Política, v.1, nº 16, 2013.

BRASIL. Constituição da República Federativa do Brasil, promulgada em 5 de outubro de 1988.

BRASIL. Lei no 6.938, de 31 de agosto de 1981.Política Nacional do Meio Ambiente. Disponível em <http://www.planalto.gov.br/ccivil 03/l eis/L6938.htm>, Acessado em: 20 de jun. de 2018.

BRASIL.Lei no 9.985, de 18 de junho de 2000.Sistema Nacional de Unidades de Conservação da Natureza. Disponível em: $<$ http://www.mma.gov.br/port/conama/legiabre.cfm?codlegi=322>. Acessado em: 28 de jun. de 2018.

CASAGRANDE JÚNIOR, E. F. Inovação tecnológica e sustentabilidade: possíveis ferramentas para uma necessária interface. Revista Educação \& Tecnologia, Curitiba, v. 8, p. 97-109, 2004. 
ESPADA, A.L.V.; SOBRINHO, M. V.; ROCHA, G. M.; VASCONCELOS, A. M. A. Manejo Florestal Comunitário na Amazônia Brasileira: O caso da Flana do Tapajós. Revista Brasileira de Gestão e Desenvolvimento Regional, v.13, n.3, p. 342-372,2017.

FARAH, M. F. S. Análise de políticas públicas no Brasil: de uma prática não nomeada à institucionalização do "campo de públicas", Revista Administração Pública, Rio de Janeiro, 50(6):959-979, nov./dez. 2016.

GOUVEIA, N. Resíduos sólidos urbanos: impactos socioambientais e perspectiva de manejo sustentável com inclusão social, Ciênc. saúde coletiva, vol.17 n⒍ Rio de Janeiro Jan/Jun2012.

HONDA, Y. F.; SOBRINHO, M. V.Análise Das Práticas De Uso E Ocupação Humana da Área de Proteção Ambiental da llha de Algodoal, Anais...IX Colóquio Organização, Desenvolvimento e Sustentabilidade - CODS e II Congresso Brasileiro de Gestão v.9 (2018) ISSN: 2526-9518. Disponível em: $<$ http://revistas.unama.br/index.php/coloquio/article/view/1103/pdf $>$.

Acessado em: 20 nov. 2018.

JACOBI, P. Educação ambiental, Cidadania e sustentabilidade Cadernos de Pesquisa, n. 118, p. 189-205, 2003.

LOCKS, P. Formulação de agenda, políticas públicas e economia solidária no Brasil, 2014. Otra Economía, v.8, n.14, pp.45-59, enero-junio 2014.

OLIVEIRA, J. G.; QUINTANA, J. G. Políticas Públicas, Sustentabilidade e Meio Ambiente: meios para a realização do Estado Socioambiental de Direito, Anais... XIII Seminário Nacional de Dinâmicas Sociais e Políticas Públicas na Sociedade Contemporânea: UNISC/ ISBN 2447-8229, 2017. Disponível em <http://online.unisc.br/acadnet/anais/index.php/snpp/article /view/16904>, Acessado em: 10 Jun.2018.

MELO, R. S.; MONTEIRO, M. S. L.; BRITO, A. S. Desenvolvimento Turístico e Sustentabilidade na Unidade de Conservação APA do Delta do Parnaíba (PI). Revista Brasileira de Ecoturismo, São Paulo, v.11, n.3, ago/out 2018, pp.335-361.

MINISTÉRIO DO MEIO AMBIENTE Ecoturismo: visitar para conservar e desenvolver a Amazônia, Brasília, MMA/SCA/PROECOTUR, 2002. Disponível em http://www.mma.gov.br/estruturas/sedr proecotur/ publica cao/140 publicacao04022009113510.pdf. Acessado em: 9 set. 2018.

NORONHA, A.N. Conceitos básicos em Políticas Públicas no Brasil contemporâneo. Revista de desenvolvimento Regional: G\&DR, v.2, n.2, pp.74-86, mai-ago/2006.

PARÁ. Secretaria de Estado de Meio Ambiente. Plano de manejo da Área de Proteção Ambiental de Algodoal-Maiandeua, Belém, 2012. Disponível em <http://ideflorbio.pa.gov.br/wp-content/uploads/2014/10/Plano-de-Manejo -APAAlgodoal-Maiandeua-v2 \%C3\%BAltimo adriana final 29.08.2012.pdf $>$ Acessado em: 20 Jul. 2018. 
PARÁ, Secretaria de Estado de Meio Ambiente. Roteiro Metodológico para Elaboração de Plano de Manejo das Unidades de Conservação do Estado do Pará. Belém: SEMA, 2009. Disponível em $<$ http://ideflorbio.pa.gov.br/wp-content/uploads/2014/10/Roteiro-Metodologico .pdf $>$. Acessado em: 20 Jul. 2018.

SALDANHA, M.A.; BELLO, L.A.L.; VINAGRE, M.A.A.; LOPES, M.L.B. As relações do Turismo com a produção de resíduos sólidos na cidade de Barreirinhas (MA). Revista Brasileira de Ecoturismo, São Paulo, v.9, n.2, mai/jul 2016, pp.366-389.

SEBRAE. Políticas Públicas: conceitos e práticas, Belo Horizonte - MG, 2008.Disponível http://www.mp.ce.gov.br/nespeciais/promulher/manuais/MA NUAL\%20DE\%20POLITICAS\%20P\%C3\%9ABLICAS.pdf. Acessado em: 19 Jul. 2018

SOUZA, C. Políticas Públicas: uma revisão da literatura. Sociologias, Porto Alegre, ano 8, no 16, jul/dez 2006.

VIDAL, M. R.; MASCARENHAS, A. L. S. Dos componentes ambientais a realidade das formas de uso e Ocupação no litoral paraense: pensando 0 caso da ilha de Algodoal-maiandeu-pa. Revista Geonorte, Edição Especial, V.3, N.4, p. 911-920, 2012.

\section{Notas:}

1 Eco-92: Conferência das Nações Unidas sobre o Meio Ambiente e Desenvolvimento, realizada em junho de 1992 no Rio de Janeiro.

${ }^{2}$ Lei ํo 9.985, de 18 de junho de 2000 Art. 2o Para os fins previstos nesta Lei, entende-se por: I - unidade de conservação: espaço territorial e seus recursos ambientais, incluindo as águas jurisdicionais, com características naturais relevantes, legalmente instituído pelo Poder Público, com objetivos de conservação e limites definidos, sob regime especial de administração, ao qual se aplicam garantias adequadas de proteção. 
Julio de Pádua Lopes Menezes: Universidade da Amazônia, Belém, PA, Brasil.

E-mail: julio.menezesi2013@gmail.com

Link para o currículo Lattes: http://lattes.cnpq.br/7668901069325950

Marco Valério de Albuquerque Vinagre: Universidade da Amazônia, Belém, PA, Brasil.

E-mail:valeriovinagre@gmail.com

Link para o currículo Lattes: http://lattes.cnpq.br/8044094535697705

Mayra Hermínia Simões Hamad Farias do Couto: Universidade da Amazônia, Belém, PA, Brasil.

E-mail:mayrahamad@gmail.com

Link para o currículo Lattes: http://lattes.cnpq.br/7809271692824225

Igor Charles Castor Alves: Universidade da Amazônia, Belém, PA, Brasil.

E-mail: igor.charles@unama.br

Link para o currículo Lattes: http://lattes.cnpq.br/5847621861708096

Kamila Batista da Silva Barbosa: Instituto Federal de Educação, Ciência e Tecnologia do Pará, Ananindeua, PA, Brasil.

E-mail:kmyla.barbosa@gmail.com

Link para o currículo Lattes: http://lattes.cnpq.br/9030609587145865

Data de submissão: 11 de dezembro de 2018

Data de recebimento de correções: 25 de dezembro de 2018

Data do aceite: 25 de dezembro de 2018

Avaliado anonimamente 